\title{
Displacement and Identity in Ahdaf Soueif's Sandpiper and Melody
}

\author{
Mira Hafsi \\ Department of English Language and Literature \\ Mohamed Lamine Debaghine University Setif -2 \\ Algeria
}

\begin{abstract}
This paper presents a literary study that is concerned with the experience of crossing cultures and theme of not belonging. It examines the condition of displacement and its effects on the identity of the female protagonists in two short stories written by Ahdaf Soueif: Sandpiper and Melody. The researcher's investigation relies on recent postcolonial criticism provided by Edward Said, Gayatri Spivak and Homi Bhabha. As such, this paper explores: the representation of the Arab culture in the the Western thought; the way linguistic hegemony is subverted through the use of a hybridized version of English; and the agency of the subaltern through using the English language as a vehicle for the transmission of Diasporic Arab female voices and concerns. This paper concludes that Ahdaf Soueif succeeds in painting an original view of the effect of the state of displacement on the psyche of her female subjects, highlighting the semi-autobiographical aspect which is used as a means to express a quest for identity. The writer also succeeds in writing back to the colonial metropolis against the hegemonic imperialist discourse. Moreover, the writer goes beyond postcolonial writing in her literary endeavor as an appeal towards developing approaches for the modern-day challenges of globalization.
\end{abstract}

Keywords: Arab women writing, diaspora, postcolonial, identity, representation

Cite as: Hafsi, M. (2017). Displacement and Identity in Ahdaf Soueif's Sandpiper and Melody. Arab World English Journal for Translation \& Literary Studies, 1(4).

DOI: http://dx.doi.org/10.24093/awejtls/vol1no4.7 